\title{
ARTIGOS
}

\section{MORTALIDADE POR ESQUISTOSSOMOSE NO BRASIL, 1977-1986}

\section{Antônio Carlos Silveira, Maria de Fátima Brandāo Vasconcelos e José Evandro Machado Melo}

\begin{abstract}
Os autores apresentam dados de mortalidade por esquistossomose no pais, macrorregiōes e unidades federadas, no periodo de 1977-1986, e relacionam os coeficientes de mortalidade com o programa de controle. O impacto se demonstra evidente, especialmente em função da população para a qual o risco de reinfecção foi reduzido ou eliminado. São apresentados também dados relativos a mortalidade proporcional e distribuiçáo por idade.
\end{abstract}

Palavras-chaves: Esquistossomose. Mortalidade por esquistossomose.P rograma Especial de Controle da Esquistossomose. Medicação em larga escala.

São muitos os dados disponiveis sobre prevalência por esquistossomose no pais ${ }^{9}$. Ao contrário, são poucos ou quase inexistentes os trabalhos sobre mortalidade por esquistossomose. Em estudo promovido por Kloetzel ${ }^{6}$ no município de Gameleira (Pernambuco), em que foram acompanhados ao todo 678 pacientes, dos quais 105 com esplenomegalia crônica, ocorreram 19 óbitos, tendo sido 11 deles atribuidos a esquistossomose $(58 \%)$.

A letalidade por esquistossomose admite-se ser baixa, a começar pelo fato de que apenas uma pequena proporção de casos evolui para formas graves da doença 7 10. A expressão clínica, ou severidade do quadro clínico, depende primariamente da carga parasitária, mas não exclusivamente, pois o estado nutricional, outras parasitoses ou condições mórbidas, suscetibilidade, resistência a reinfestações e raça do indivíduo parasitado, teriam também importâncial 3512 .

A partir da introdução de novas drogas, administradas em dose única, e de seu emprego em larga escala, observou-se significativa redução no número de casos que desenvolvem formas graves de esquistossomose ${ }^{128}$. Há evidências de que outras medidas podem contribuir ao menos para a redução da forma hepatoesplênica 711 .

Com base nesses dados, formulou-se a hipótese de que a diminuição observada, e adiante comprovada, no número de casos de formas graves, deveria ter

Superintendência de Campanhas de Saúde Pública (SUCAM). Ministério da Saúde, Brasilia, DF.

Endereço para correspondência: Dr. Antônio Carlos Silveira, Anexo do Ministério da Saúde, Bloco G, Ala B, 3. andar, Sala 351. 70058 Brasilia, DF.

Recebido para publicação em 22/06/90. determinado impacto equivalente sobre a mortalidade atribuida a esquistossomose.

\section{MATERIAL E MÉTODOS}

O Sistema de Informações de Mortalidade (SIM) da Divisão Nacional de Epidemiologia (DNE) da Secretaria Nacional de Ações Básicas de Saúde do Ministério da Saúde (SNABS/MS), a partir de 1977 passou a sistematizar a coleta, processamento e difusão de dados de mortalidade, por município de residência e segundo causa básica atribuida ao óbito. Os dados são ainda distribuidos segundo variáveis como grupo de idade.

Mesmo que a cobertura do sistema, que considera os registros oficiais de óbito seja, em alguns casos, baixa (Tabelas 1 e 2), e que imprecisões na classificação sejam com alguma freqüência observadas, a crítica regular e depuração dos dados fazem com que tenham suficiente consistência, ao menos ao nivel de agregação e análise por nós pretendida.

Partindo então desses dados secundários, reunidos e processados pela DNE/SNABS, calculou-se coeficientes de mortalidade específica por esquistossomose (CID 120.1) por unidade federada e macrorregiões; coeficientes de mortalidade proporcional em relação ao total de óbitos e a óbitos por doenças infecciosas e parasitárias, a cada ano para a série estudada (1977/86).

No sentido de ter o máximo aproveitamento dos dados disponiveis fez-se a distribuição dos óbitos por grupos de idade, e calculou-se a participação relativa de cada um desses grupos, o que serviu à determinação, de forma bastante confiável - considerando que foram reunidos dados correspondentes a dez anos - do padrão de mortalidade por esquistossomose segundo a 
Silveira AC, Vasconcelos MFB, Melo JEM. Mortalidade por esquistossomose no Brasil, 1977-1986. Revista da Sociedade Brasileira de Medicina Tropical 23: 133-140, jul-set, 1990.

Tabela 1 - Cobertura (\%) do sistema de informações sobre mortalidade, segundo o número de municípios com informação regular, por unidade da federação 1977-1985.

\begin{tabular}{|c|c|c|c|c|c|c|c|c|c|}
\hline \multirow{2}{*}{$\begin{array}{l}\text { Macrorregião e } \\
\text { Unidade Federada }\end{array}$} & \multicolumn{9}{|c|}{ Ano } \\
\hline & 1977 & 1978 & 1979 & 1980 & 1981 & 1982 & 1983 & 1984 & 1985 \\
\hline Norte & 34,4 & 44,4 & 50,3 & 53,5 & 51,6 & 50,3 & 50,5 & 57,9 & 32,7 \\
\hline Rondônia & 100,0 & 85,7 & 100,0 & 100,0 & 100,0 & 100,0 & 100,0 & 92,3 & 66,6 \\
\hline Acre & 58,3 & 58,3 & 58,3 & 58,3 & 58,3 & 50,0 & 50,0 & 50,0 & 25,0 \\
\hline Amazonas & 2,2 & 25,0 & 29,5 & 29,5 & 20,4 & 22,7 & 22,7 & 34,0 & 18,1 \\
\hline Roraima & 50,0 & 50,0 & 50,0 & 50,0 & 100,0 & 100,0 & 25,0 & 62,5 & 25,0 \\
\hline Pará & 46,9 & 50,6 & 54,2 & 60,2 & 60,2 & 59,0 & 60,9 & 65,5 & 36,7 \\
\hline Amapá & 20,0 & 20,0 & 80,0 & 80,0 & 80,0 & 60,0 & 49,0 & 60,0 & 20,0 \\
\hline Nordeste & 20,9 & 23,3 & 37,8 & 57,6 & 58,4 & 62,1 & 70,8 & 72,3 & 53,7 \\
\hline Maranhão & 0,7 & 7,6 & 9,2 & 9,2 & 8,4 & 23,8 & 55,3 & 57,5 & 14,3 \\
\hline Piaui & 0,8 & 0,8 & 3,5 & 17,5 & 13,1 & 33,3 & 44,3 & 55,6 & 36,5 \\
\hline Ceará & 0,7 & 0,7 & 9,9 & 13,4 & 22,6 & 24,1 & 60,2 & 58,1 & 21,6 \\
\hline Rio G. do Norte & 0,6 & 8,6 & 12,0 & 70,0 & 64,0 & 50,6 & 49,6 & 56,2 & 49,0 \\
\hline Paraíba & 0,5 & 0,5 & 9,3 & 91,2 & 90,6 & 89,4 & 88,8 & 87,7 & 76,0 \\
\hline Pernambuco & 89,6 & 90,8 & 90,2 & 92,6 & 95,7 & 92,6 & 95,8 & 96,4 & 87,4 \\
\hline Alagoas & 1,0 & 1,0 & 95,7 & 93,6 & 88,2 & 95,7 & 97,9 & 96,8 & 76,0 \\
\hline F. Noronha & 100,0 & 100,0 & 100,0 & 100,0 & 100,0 & 100,0 & 100,0 & 100,0 & 100,0 \\
\hline Sergipe & 1,3 & 1,3 & 91,8 & 91,8 & 95,9 & 94,5 & 95,9 & 89,1 & 68,9 \\
\hline Bahia & 39,5 & 42,5 & 44,3 & 50,8 & 54,4 & 62,2 & 65,1 & 66,6 & 48,5 \\
\hline Sudeste & 93,9 & 97,5 & 97,5 & 97,3 & 96,8 & 97,5 & 96,3 & 96,1 & 92,3 \\
\hline Minas Gerais & 95,4 & 95,9 & 95,5 & 95,1 & 94,1 & 95,2 & 93,3 & 92,5 & 87,9 \\
\hline Espirito Santo & 0,0 & 94,3 & 96,2 & 96,2 & 96,2 & 98,1 & 98,2 & 98,2 & 96,5 \\
\hline Rio de Janeiro & 100,0 & 98,4 & 100,0 & 100,0 & 100,0 & 100,0 & 98,4 & 100,0 & 100,0 \\
\hline São Paulo & 100,0 & 99,8 & 99,8 & 99,8 & 100,0 & 100,0 & 99,6 & 100,0 & 96,5 \\
\hline Sul & 94,8 & 96,8 & 96,8 & 98,1 & 97,3 & 98,1 & 96,5 & 98,0 & 86,4 \\
\hline Paraná & 93,7 & 97,2 & 97,2 & 98,6 & 98,9 & 99,6 & 97,4 & 98,3 & 85,4 \\
\hline S. Catarina & 90,3 & 92,3 & 92,3 & 95,4 & 91,8 & 93,9 & 90,9 & 94,9 & 75,8 \\
\hline Rio G. do Sul & 100,0 & 100,0 & 100,0 & 100,0 & 100,0 & 100,0 & 100,0 & 100,0 & 96,3 \\
\hline Centro-Oeste & 10,7 & 11,0 & 29,9 & 38,9 & 61,3 & 58,1 & 73,0 & 81,1 & 51,4 \\
\hline Mato Grosso & 34,4 & 35,4 & 16,3 & 20,0 & 23,6 & 73,3 & 43,1 & 53,4 & 31,0 \\
\hline Mato G. do Sul & - & - & 34,5 & 60,0 & 69,0 & 32,7 & 70,3 & 78,1 & 48,4 \\
\hline Goiás & 0,4 & 0,4 & 31,8 & 38,1 & 68,6 & 86,9 & 70,7 & 88,5 & 56,9 \\
\hline D. Federal & 100,0 & 100,0 & 100,0 & 100,0 & 100,0 & 100,0 & 100,0 & 100,0 & 100,0 \\
\hline Brasil & 59,9 & 62,8 & 69,3 & 77,2 & 79,0 & 81,6 & 83,7 & 85,5 & 72,0 \\
\hline
\end{tabular}

Fonte: DNE/SNABS/MS

idade. Além disso, calculou-se os anos potenciais de vida perdidos (APVP), mesmo que no caso da esquistossomose, sendo doença de caráter crônico, em que a maior parte dos óbitos ocorre tardiamente, não seja um indicador muito útil ou apropriado à demonstração da importância da doença.

No estudo da associação dos coeficientes de mortalidade com o tempo, por unidade federada e macrorregião, utilizou-se o teste de regressão linear.

\section{RESULTADOS}

Um primeiro registro a fazer, e que pode representar viés importante, é que os dados correspondentes, ao menos aos dois ou três primeiros anos da série $1977 / 86$, se referem, no caso de vários dos Estados (Amazonas, Amapá, Maranhão, Piauí, Ceará, Rio Grande do Norte, Paraiba, Alagoas, Sergipe e Goiás), apenas aos municípios das capitais. 
Silveira AC, Vasconcelos MFB, Melo JEM. Mortalidade por esquistossomose no Brasil, 1977-1986. Revista da Sociedade Brasileira de Medicina Tropical 23: 133-140, jul-set, 1990.

Tabela 2 - Cobertura (\%) do sistema de informações sobre mortalidade segundo a populaf̧ão dos municipios com infor mação regular, por unidade da federação 1977-1985.

\begin{tabular}{|c|c|c|c|c|c|c|c|c|c|}
\hline \multirow{2}{*}{$\begin{array}{l}\text { Macrorregião e } \\
\text { Unidade Federada }\end{array}$} & \multicolumn{9}{|c|}{ Ano } \\
\hline & 1977 & 1978 & 1979 & 1980 & 1981 & 1982 & 1983 & 1984 & 1985 \\
\hline Norte & 58,8 & 69,0 & 75,7 & 78,3 & 75,8 & 76,3 & 75,4 & 78,5 & 69,8 \\
\hline Rondônia & 100,0 & 93,8 & 100,0 & 100,0 & 100,0 & 100,0 & 100,0 & 96,0 & 71,1 \\
\hline Acre & 88,8 & 87,4 & 88,8 & 88,7 & 88,8 & 82,5 & 82,3 & 79,0 & 51,2 \\
\hline Amazonas & 40,7 & 60,5 & 67,9 & 66,9 & 63,7 & 67,4 & 68,8 & 73,6 & 63,5 \\
\hline Roraima & 86,7 & 85,4 & 84,5 & 84,5 & 100,0 & 100,0 & 71,1 & 80,3 & 71,1 \\
\hline Pará & 57,8 & 67,3 & 74,0 & 78,2 & 74,4 & 74,7 & 73,2 & 77,2 & 73,2 \\
\hline Amapá & 77,6 & 77,8 & 88,3 & 94,5 & 97,1 & 86,6 & 84,6 & 83,7 & 77,8 \\
\hline Nordeste & 42,8 & 46,6 & 58,8 & 68,1 & 68,5 & 73,1 & 79,9 & 81,0 & 63,9 \\
\hline Maranhão & 10,5 & 27,4 & 30,0 & 29,1 & 26,6 & 48,5 & 68,1 & 68,6 & 26,1 \\
\hline Piaui & 16,2 & 16,5 & 25,6 & 38,6 & 38,7 & 57,6 & 61,6 & 70,8 & 53,8 \\
\hline Ceará & 23,1 & 23,5 & 34,0 & 40,3 & 48,4 & 49,1 & 70,0 & 71,5 & 48,8 \\
\hline Rio G. Norte & 20,4 & 36,8 & 48,5 & 84,0 & 71,6 & 64,4 & 65,2 & 67,5 & 62,4 \\
\hline Paraíba & 11,0 & 11,2 & 38,1 & 95,9 & 94,9 & 94,4 & 94,1 & 93,5 & 86,5 \\
\hline Pernambuco & 94,3 & 94,3 & 94,7 & 95,0 & 96,8 & 94,6 & 97,5 & 95,9 & 90,9 \\
\hline Alagoas & 19,0 & 19,2 & 97,5 & 96,7 & 93,9 & 97,9 & 99,3 & 99,2 & 87,9 \\
\hline F. Noronha & 100,0 & 100,0 & 100,0 & 100,0 & 100,0 & 100,0 & 100,0 & 100,0 & 100,0 \\
\hline Sergipe & 24,1 & 24,5 & 96,5 & 97,3 & 98,0 & 98,0 & 98,5 & 94,6 & 79,9 \\
\hline Bahia & 60,5 & 64,1 & 64,1 & 68,5 & 68,9 & 73,9 & 75,8 & 78,2 & 60,9 \\
\hline Sudeste & 95,3 & 99,2 & 99,1 & 99,1 & 98,9 & 99,2 & 99,1 & 98,8 & 98,1 \\
\hline Minas Gerais & 97,4 & 97,8 & 97,1 & 97,3 & 96,2 & 97,3 & 96,8 & 95,5 & 93,3 \\
\hline Espirito Santo & - & 96,3 & 96,7 & 96,7 & 97,0 & 97,2 & 99,4 & 99,4 & 98,7 \\
\hline Rio de Janeiro & - & 100,0 & 99,7 & 100,0 & 100,0 & 100,0 & 99,7 & 100,0 & 100,0 \\
\hline São Paulo & 100,0 & 100,0 & 99,9 & 100,0 & 100,0 & 100,0 & 99,9 & 100,0 & 99,7 \\
\hline Sul & 97,5 & 98,4 & 98,6 & 99,4 & 98,9 & 99,3 & 98,0 & 98,9 & 89,9 \\
\hline Paraná & 96,2 & 98,1 & 98,4 & 99,5 & 99,8 & 99,4 & 98,0 & 98,5 & 84,7 \\
\hline Santa Catarina & 95,0 & 95,7 & 95,9 & 98,1 & 94,8 & 97,5 & 94,1 & 97,7 & 82,1 \\
\hline Rio G. do Sul & 100,0 & 100,0 & 100,0 & 100,0 & 100,0 & 100,0 & 100,0 & 100,0 & 98,4 \\
\hline Centro-Oeste & 40,8 & 41,7 & 62,2 & 69,8 & 78,5 & 82,6 & 85,0 & 87,4 & 72,7 \\
\hline Mato Grosso & 55,2 & 55,8 & 43,9 & 47,8 & 49,4 & 53,9 & 62,6 & 64,8 & 47,6 \\
\hline Mato G. do Sul & - & - & 59,3 & 80,4 & 83,3 & 75,5 & 83,5 & 88,1 & 71,9 \\
\hline Goiás & 16,7 & 17,1 & 57,5 & 63,4 & 78,9 & 88,4 & 87,7 & 90,2 & 71,7 \\
\hline D. Federal & 100,0 & 100,0 & 100,0 & 100,0 & 100,0 & 100,0 & 100,0 & 100,0 & 100,0 \\
\hline Brasil & 75,2 & 78,6 & 83,7 & 87,2 & 87,6 & 89,3 & 91,2 & 91,8 & 83,7 \\
\hline
\end{tabular}

Fonte: DNE/SNABS/MS

Isso significa de inicio que, o aumento do número de óbitos entre 1977/80 pode não ser real, e que teria sido influenciado pela incorporação de novas áreas com informação regular ao sistema.

$O$ exame das Tabelas 3 e 4 revela:

19) diferente participação, no total de óbitos por esquistossomose, das diferentes macrorregiōes do pais. Tomando por exemplo o ano de 1986, maior concentração na região Nordeste $(1,07 / 100.000$ habitantes); e, aí, nos Estados de Alagoas (4,18/100.000),
Pernambuco $(3,16 / 100.000)$ e Sergipe $(1,14 / 100.000)$ o que concorda com os dados conhecidos de morbidade;

2.) ainda em 1986 houve coeficientes de mortalidade relativamente altos em dois outros Estados, onde a esquistossomose não é reconhecida comoproblema de maior magnitude ou expressão - Espírito Santo (1,37/100.000 habitantes) e Rondonia( $(1,33 / 100.000)$;

3o) redução significativa dos coeficientes de mortalidade a partir de 1980 para o pais $(0,70 / 100.000 \mathrm{em}$ 
Silveira AC, Vasconcelos MFB, Melo JEM. Mortalidade por esquistossomose no Brasil, 1977-1986. Revista da Sociedade Brasileira de Medicina Tropical 23: 133-140, jul-set, 1990.

Tabela 3 - Número de óbitos por esquistossomose por unidade federada, Brasil, 1977-1986.

\begin{tabular}{|c|c|c|c|c|c|c|c|c|c|c|}
\hline \multirow{2}{*}{$\begin{array}{l}\text { Macrorregião e } \\
\text { Unidade Federada }\end{array}$} & \multicolumn{10}{|c|}{ Ano } \\
\hline & 1977 & 1978 & 1979 & 1980 & 1981 & 1982 & 1983 & 1984 & 1985 & 1986 \\
\hline Norte & 1 & 7 & 1 & 10 & 5 & 5 & 11 & 7 & 8 & 20 \\
\hline Rondônia & 1 & 3 & 1 & 7 & 3 & 4 & 9 & 7 & 8 & 16 \\
\hline Acre & - & 1 & - & - & - & - & - & - & - & 2 \\
\hline Amazonas & - & - & - & - & - & - & - & - & - & 1 \\
\hline Roraima & - & - & - & - & - & - & - & - & - & - \\
\hline Pará & - & 3 & - & 3 & 2 & 1 & 2 & - & - & 1 \\
\hline Amapá & - & - & - & - & - & - & - & - & - & - \\
\hline Nordeste & 366 & 323 & 411 & 448 & 415 & 394 & 457 & 435 & 424 & 422 \\
\hline Maranhão & 11 & 22 & 9 & 14 & 22 & 14 & 16 & 20 & 29 & 16 \\
\hline Piaui & - & - & 1 & - & - & - & - & - & 1 & 3 \\
\hline Ceará & - & 1 & 3 & 5 & 5 & 5 & 3 & 6 & 2 & 1 \\
\hline Rio G. do Norte & 1 & 4 & 4 & - & 3 & 10 & 5 & 3 & 5 & 10 \\
\hline Paraíba & 22 & 25 & 29 & 28 & 15 & 7 & 6 & 9 & 2 & 11 \\
\hline Pernambuco & 260 & 221 & 226 & 205 & 190 & 197 & 219 & 227 & 237 & 216 \\
\hline Alagoas & 18 & 16 & 108 & 142 & 118 & 102 & 143 & 111 & 88 & 95 \\
\hline Sergipe & 4 & 4 & 6 & 27 & 30 & 17 & 20 & 17 & 22 & 15 \\
\hline Bahia & 50 & 30 & 25 & 27 & 32 & 42 & 45 & 42 & 38 & 55 \\
\hline Sudeste & 332 & 380 & 369 & 328 & 292 & 263 & 198 & 214 & 208 & 230 \\
\hline Minas Gerais & 102 & 133 & 145 & 102 & 104 & 98 & 80 & 79 & 78 & 74 \\
\hline Espirito Santo & - & 13 & 10 & 10 & 18 & 21 & 8 & 18 & 18 & 32 \\
\hline Rio de Janeiro & 66 & 62 & 37 & 53 & 43 & 33 & 39 & 33 & 34 & 38 \\
\hline São Paulo & 164 & 172 & 177 & 163 & 127 & 111 & 71 & 84 & 78 & 86 \\
\hline Sul & 27 & 38 & 27 & 31 & 22 & 22 & 18 & 20 & 13 & 19 \\
\hline Paraná & 26 & 38 & 27 & 31 & 22 & 21 & 17 & 19 & 12 & 19 \\
\hline Santa Catarina & 1 & - & - & - & - & 1 & - & 1 & 1 & - \\
\hline Rio G. do Sul & - & - & - & - & - & - & 1 & - & - & - \\
\hline Centro-Oeste & 14 & 15 & 10 & 17 & 24 & 12 & 21 & 21 & 20 & 9 \\
\hline Mato Grosso & 1 & 2 & - & - & 1 & - & 3 & 1 & 3 & 1 \\
\hline Mato Grosso do Sul & - & - & 4 & 8 & 5 & 1 & 7 & 7 & 8 & 1 \\
\hline Goiás & 5 & 3 & 2 & 3 & 7 & 5 & 2 & 9 & 4 & 4 \\
\hline D. Federal & 8 & 10 & 4 & 6 & 11 & 6 & 9 & 4 & 5 & 3 \\
\hline Brasil & 740 & 763 & 818 & 834 & 758 & 696 & 705 & 697 & 673 & 700 \\
\hline
\end{tabular}

Fonte: DNE/SNABS/MS

1980 a $0,51 / 100.000$ em 1986), o que foi especialmente notável para a região Sudeste. Os dados para o pais, testados através de regressão linear, mostraram significativa associação com o tempo $(r=-0,024667$ $\pm 0,007434)$, muito às custas da redução dos coeficientes calculados para o Sudeste $(r=-0,5212+$ 0,0071 ); enquanto, para a região Nordeste, os coeficientes não mostraram relação estatisticamente significante com o tempo $(r=0,001103 \pm 0,0296)$.

Em relação à mortalidade proporcional por esquistossomose no grupo doenças infecciosas e parasitárias é de se observar que a participação, em termos percentuais, da esquistossomose como causa de óbito, experimentou aumento considerável, mesmo que $o$ número absoluto de óbitos tenha se mantido estável a partir de 1981. Ao contrário, o total de óbitos no grupo de infecciosas e parasitárias, sofreu importante redução no periodo (Tabela 5).

A distribuição por idade mostrou que a mortalidade por esquistossomose é acontecimento raro em menores de 20 anos, com aproximadamente $7 \%$ do total conhecido. Já no grupo de 20 a 29 anos de idade ocorreram $13,7 \%$ cios óbitos, o que contribuiu para que o percentual acumulado para menores de 30 anos 
Silveira AC, Vasconcelos MFB, Melo JEM. Mortalidade por esquistossomose no Brasil, 1977-1986. Revista da Sociedade Brasileira de Medicina Tropical 23: 133-140, jul-set, 1990.

Tabela 4-Coeficiente de mortalidade especifica (100.000 hab.) por esquistossomose, por unidade federada, Brasil. 1977-1986.

\begin{tabular}{|c|c|c|c|c|c|c|c|c|c|c|}
\hline \multirow{2}{*}{$\begin{array}{l}\text { Macrorregião e } \\
\text { Unidade Federada }\end{array}$} & \multicolumn{10}{|c|}{ Ano } \\
\hline & 1977 & 1978 & 1979 & 1980 & 1981 & 1982 & 1983 & 1984 & 1985 & 1986 \\
\hline Norte & 0,02 & 0,13 & 0,02 & 0,17 & 0,08 & 0,08 & 0,16 & 0,10 & 0,10 & 0,24 \\
\hline Rondônia & 0,32 & 0,84 & 0,24 & 1,45 & 0,56 & 0,69 & 1,46 & 1,06 & 0,88 & 1,33 \\
\hline Acre & - & 0,35 & - & - & - & - & - & - & - & 0,54 \\
\hline Amazonas & - & - & - & - & - & - & - & - & - & 0,05 \\
\hline Roraima & - & - & - & - & - & - & - & - & - & - \\
\hline Pará & - & 0,10 & - & 0,09 & 0,05 & 0,03 & 0,05 & - & - & 0,02 \\
\hline Amapá & - & - & - & - & - & - & - & - & - & - \\
\hline Nordeste & 1,12 & 0,97 & 1,20 & 1,29 & 1,16 & 1,08 & 1,23 & 1.14 & 1,09 & 1,07 \\
\hline Maranhão & 0,30 & 0,58 & 0,23 & 0,35 & 0,53 & 0,33 & 0,37 & 0,45 & 0,63 & 0,33 \\
\hline Piauí & - & - & 0,05 & - & - & - & - & - & 0,04 & 0,12 \\
\hline Ceará & - & 0,02 & 0,06 & 0,09 & 0,09 & 0,09 & 0,05 & 0,10 & 0,03 & 0,02 \\
\hline Rio G. do Norte & 0,05 & 0,22 & 0,21 & - & 0,15 & 0,50 & 0,25 & 0,14 & 0,24 & 0,47 \\
\hline Paraiba & 0,83 & 0,93 & 1,06 & 1,01 & 0,53 & 0,24 & 0,20 & 0,30 & 0,07 & 0,36 \\
\hline Pernambuco & 4,47 & 3,73 & 3,75 & 3,34 & 3,02 & 3,08 & 3,37 & 3,43 & 3,50 & 3,16 \\
\hline Alagoas & 0,97 & 0,84 & 5,58 & 7,17 & 5,79 & 4,90 & 6,73 & 5,12 & 3,95 & 4,18 \\
\hline Sergipe & 0,38 & 0,37 & 0,54 & 2,37 & 2,55 & 1,42 & 1,63 & 1,36 & 1,70 & 1,14 \\
\hline Bahia & 0,57 & 0,33 & 0,27 & 0,28 & 0,33 & 0,42 & 0,44 & 0,40 & 0,35 & 0,50 \\
\hline Sudeste & 0,70 & 0,78 & 0,73 & 0,63 & 0,55 & 0,48 & 0,35 & 0,37 & 0,35 & 0,38 \\
\hline Minas Gerais & 0,80 & 1,02 & 1,10 & 0,76 & 0,76 & 0,70 & 0,57 & 0,55 & 0,53 & 0,50 \\
\hline Espírito Santo & $\cdots$ & 0,67 & 0,50 & 0,49 & 0,86 & 0,99 & 0,37 & 0,81 & 0,79 & 1,37 \\
\hline Rio de Janeiro & 0,63 & 0,57 & 0,33 & 0,47 & 0,37 & 0,28 & 0,32 & 0,27 & 0,27 & 0,29 \\
\hline São Paulo & 0,73 & 0,74 & 0,73 & 0,65 & 0,49 & 0,41 & 0,26 & 0,30 & 0,26 & 0,28 \\
\hline Sul & 0,15 & 0,20 & 0,14 & 0,16 & 0,11 & 0,11 & 0,09 & 0,10 & 0,06 & 0,09 \\
\hline Paraná & 0,35 & 0,50 & 0,35 & 0,40 & 0,28 & 0,26 & 0,21 & 0,24 & 0,15 & 0,23 \\
\hline Santa Catarina & 0,03 & - & - & - & - & 0,03 & - & 0,02 & 0,02 & - \\
\hline Rio G. do Sul & - & - & - & - & - & - & 0,01 & - & - & - \\
\hline Centro-Oeste & 0,21 & 0,22 & 0,14 & 0,22 & 0,30 & 0,15 & 0,25 & 0,24 & 0,22 & 0,11 \\
\hline Mato Grosso & 0,05 & 0,09 & - & - & 0,83 & - & 0,23 & 0,07 & 0,20 & 0,06 \\
\hline Mato G. do Sul & - & - & 0,30 & 0,58 & 0,35 & 0,07 & 0,47 & 0,45 & 0,50 & 0,06 \\
\hline Goiás & 0,14 & 0,08 & 0,05 & 0,08 & 0,17 & 0,12 & 0,05 & 0,21 & 0,09 & 0,11 \\
\hline D. Federal & 0,87 & 1,01 & 0,37 & 0,51 & 0,88 & 0,45 & 0,65 & 0,27 & 0,32 & 0,23 \\
\hline Brasil & 0,67 & 0,68 & 0,70 & 0,70 & 0,62 & 0,55 & 0,55 & 0,53 & 0,50 & 0,51 \\
\hline
\end{tabular}

Fonte: DNE/SNABS/MS

tenha alcançado a $20,7 \%$. Considerado o caráter crônico da enfermidade, esse dado não é absolutamente desprezível, mesmo que mais de $60 \%$ dos óbitos tenham ocorrido após os $\mathbf{4 0}$ anos, e mais de $\mathbf{4 0 \%}$ após os 50 anos de idade (Tabela 6).

Esse padrão de mortalidade faz com que a APVP năo seja indicador de maior importâncía. Ainda assim, chegou-se a um total, para o periodo, de 143.548 anos potenciais de vida perdidos (Tabela 7).

\section{DISCUSSÃO}

Quando examinados os dados para o país e o coeficiente de correlação com o tempo, o impacto das atividades de controle sobre a mortalidade por esquistossomose foi grande.

O uso da medicação específica (oxamniquine) em larga escala foi introduzido em 1976/77, tendo alcançado nos três anos subseqüentes $(1978 / 80)$ a mais de 1 milhão de tratamentos/ano e, desde quando 
Silveira AC, Vasconcelos MFB, Melo JEM. Mortalidade por esquistossomose no Brasil, 1977-1986. Revista da Sociedade Brasileira de Medicina Tropical 23: 133-140, jul-set, 1990.

Tabela 5-Mortalidade proporcional (\%) por esquistossomose, em relaçāo ao total de óbitos por doenças infecciosas $e$ parasitárias, por ano, Brasil, 1977-1986.

\begin{tabular}{cccc}
\hline & \multicolumn{2}{c}{ No de Óbitos } & $\begin{array}{c}\text { \% de Óbitos } \\
\text { por Esquistossomose }\end{array}$ \\
\cline { 2 - 4 } & Doenças Infecciosas & Esquistossomose & 0,93 \\
1977 & 79.725 & 740 & 0,95 \\
1978 & 80.485 & 763 & 1,12 \\
1980 & 73.054 & 818 & 1,20 \\
1981 & 69.553 & 834 & 1,18 \\
1982 & 64.163 & 758 & 1,17 \\
1983 & 59.404 & 696 & 1,22 \\
1984 & 57.598 & 705 & 1,15 \\
1985 & 60.751 & 697 & 1,35 \\
\hline 1986 & 49.946 & 673 & 1,37 \\
\hline
\end{tabular}

Fonte: DNE/SNABS/MS

Tabela 6 - Número de óbitos por esquistossomose, percentual e percentual acumulado por grupo de idade, Brasil, periodo 1977-1986.

\begin{tabular}{crrc}
\hline Idade & No de Óbitos & \multicolumn{1}{c}{$\%$} & \% Acumulado \\
\hline$<10$ & 93 & 1,26 & - \\
$10-19$ & 420 & 5,69 & 6,95 \\
$20-29$ & 1.014 & 13,73 & 20,68 \\
$30-39$ & 1.224 & 16,57 & 37,25 \\
$40-49$ & 1.521 & 20,60 & 57,85 \\
$>50$ & 3.082 & 41,73 & 99,58 \\
Ignorado & 31 & 0,42 & - \\
\hline Todas Idades & 7.385 & 100,0 & 100,0 \\
\hline
\end{tabular}

Fonte: DNE/SNABS/MS iniciado o Programa Especial de Controle da Esquistossomose (PECE) até 1986, que corresponde ao último ano para o qual são disponiveis e se apresenta os dados de mortalidade, foram feitos aproximadamente 9 milhões de tratamentos ${ }^{12}$.

Por outro lado, importa considerar que as atividades do programa estiveram concentradas na região Nordeste, onde os coeficientes de mortalidade apresentaram pequeno grau de associação com o tempo. Isso sugere que outras variáveis, que não exatamente as ações de controle, interviéram na redução das taxas de mortalidade registradas para o país, por sua vez grandemente influenciadas pelos dados do Sudeste - excluído o Estado do Espirito Santo que, além de representar pouco em termos

Tabela 7-Anos potenciais de vida perdidos (APVP) entre zero e 65 anos, por esquistossomose mansônica, Brasil, 1977-1986.

\begin{tabular}{crrrrrrrrrrr}
\hline $\begin{array}{c}\text { Grupo de } \\
\text { Idade }\end{array}$ & 1977 & 1978 & 1979 & 1980 & 1981 & 1982 & 1983 & $1984(1)$ & $1985(1)$ & 1986 & Total \\
\hline$<10$ & 540 & 1020 & 660 & 480 & 600 & 180 & 540 & 605 & 385 & 480 & 5490 \\
$10-19$ & 3100 & 2850 & 3450 & 2500 & 2200 & 1800 & 1500 & 1080 & 1350 & 900 & 20730 \\
$20-29$ & 5680 & 4640 & 4400 & 5960 & 4200 & 4200 & 2920 & 2975 & 2275 & 2560 & 39810 \\
$30-39$ & 3630 & 4380 & 4620 & 4080 & 3510 & 3960 & 3360 & 2850 & 2125 & 3210 & 35725 \\
$40-49$ & 3260 & 3360 & 3380 & 3440 & 3200 & 2680 & 2760 & 2025 & 2010 & 2968 & 29083 \\
$50-64 ; 50-59(1)$ & 1177,5 & 1312,5 & 1507,5 & 1429,5 & 1477,5 & 1282,5 & 1455 & 705 & 755 & 1575 & 12710 \\
\hline Total & 17387,5 & 17562,5 & 18017,5 & 17952,5 & 15157,5 & 14102,5 & 12535 & 10240 & 8900 & 11693 & 143548 \\
\hline
\end{tabular}

(1) O cálculo dos anos 1984 e 1985 foi feito baseado na estimativa de vida média de 60 anos.

Fonte: DNE/SNABS/MS 
relativos, não acompanhou os demais Estados da região na tendência observada.

Interessa ainda considerar que o tratamento da população humana, quando do PECE, era orientado por inquéritos coproscópicos que tomava como amostra a população de 7 a 14 anos de idade e, em função da prevalência por municipio obtida nesse grupo, a medicação se fazia mais ou menos seletivamente ou, em massa se superior a $20 \%$ a positividade. Adiante, quando desativado o PECE, o tratamento em massa passou a ser feito apenas com prevalências acima de $60 \%$, também com base em amostra no grupo de 7 a 14 anos.

$\mathrm{Na}$ interpretação dos dados, importa finalmente fazer referência ao fato de que o fluxo migratório, da região Nordeste em direção ao Sudeste, não foi alterado (reduzido) nessa última década ${ }^{4}$; e que a maior parte dos óbitos atribuídos a esquistossomose na região Sudeste ocorreu entre nordestinos migrantes, especialmente entre aqueles residentes no Estado de São Paulo.

Dessas preliminares, ou a partir desse conjunto de variáveis, pensa-se possível tentar o entendimento da contradição apontada, ou seja, de que a queda havida nos coeficientes de mortalidade por esquistossomose no país, no periodo $1977 / 86$, não teria dependido do programa de controle - desde que a região Nordeste, para onde foram dirigidas as ações, aparentemente pouco contribuiu para isso.

Interessa considerar basicamente dois fatos na demonstração de que o uso da droga em larga escala produziu impacto sobre a mortalidade por esquistossomose.

A população tratada e não tratada que permaneceu no Nordeste esteve sujeita à reinfecção, enquanto o risco foi grandemente reduzido ou, em termos práticos, eliminado para a população que migrou para o Sudeste e mesmo outras áreas indenes. Com isso, e assumindo que um único tratamento é suficiente para interromper a evolução da doença, aquela parcela da população tratada, e que saiu da área com transmissão, certamente não evoluiu para o óbito. Por outro lado, um importante segmento da população residente em área endêmica do Nordeste, e que ai se manteve, não foi em nenhum momento tratada, uma vez que os inquéritos coproscópicos de rotina que serviram para determinar a extensão do tratamento, ou os grupos populacionais a serem tratados, foram feitos por amostragem em escolares de 7 a 14 anos, e o tratamento se fazia em massa apenas com altas taxas de prevalência, não alcançando por isso muitos adultos com chance de desenvolver formas graves de esquistossomose.

Dai fica claro por que o impacto do tratamento foi até aqui maior no Sudeste do que na própria região Nordeste. A população migrante de início não era tratada, e parte dela era portadora de formas graves descompensadas irreversiveis. A partir da introdução da droga e do seu uso em larga escala pelo programa, muitos dos casos que evoluiram para o óbito especialmente se afastado o risco de reinfeç̧ão deixaram de fazê-lo.

$\mathrm{O}$ segundo fato que, em alguma medida, pode ter influenciado a maior redução na mortalidade por esquistossomose na região Sudeste, foi a maior oferta e supostamente melhor assistência médica, com uso da medicação específica pelos serviços permanentes de saúde.

Quando do PECE colocava-se como objetivo do controle a redução da prevalência a niveis da ordem de $4 \%$ e, com isso, a redução da transmissão. Não era então conhecido que o tratamento, e que um único tratamento, seria suficiente para prevenir formas clínicas graves.

A partir do momento em que agora se coloca a redução da morbidade ou mesmo a prevenção da ocorrência de qualquer caso grave de esquistossomose, como o primeiro nível de controle pretendido pelo programa, o inquérito coproscópico censitário passa a ser absolutamente obrigatório, com o tratamento de rigorosamente todos os casos positivos detectáveis pelos exames de rotina. Espera-se que essa mudança introduzida na metodologia do programa determine um impacto bastante maior na mortalidade por esquistossomose nos próximos anos.

\section{SUMARY}

The authors present schistosomiasis mortality data in the country, in macrozones and in the federal units during the period of 1977-86. They relate mortality average to the control program. Its impact seems to be evident, epecially concerning the population that underwent treatment. Here the reinfection risk has been decreased or eliminated. Data referring to the proportional mortality and distribution by age are also presented.

Key-words: Schistosomiasis. Schistosomiasis mortality. Special Control Program of Schistosomiasis. Large scale medication.

\section{REFERÊNCIAS BIBLIOGRÁFICAS}

1. Bina JC. Influência da terapêutica específica na evolução da esquistossomose mansoni. Revista da Patologia Tropical 10: 221-267, 1981.

2. Bina JC, Prata A. Regressão da hepatoesplenomegalia pelo tratamento específico da esquistossomose. Revista da Sociedade Brasileira de Medicina Tropical 16: 213 $218,1983$.

3. Coutinho EM. Estado nutricional e esquistossomose. Revista da Sociedade Brasileira de Medicina Tropical 13: 91-97, 1979/80. 
4. Fundação Instituto Brasileiro de Geografia e Estatística (IBGE). Anuário Estatístico do Brasil 1987. Rio de Janeiro, 1988.

5. Kloetzel K. Some quantitative aspects of diagnosis and epidemiology in schistosomiasis mansoni. The American Journal of Tropical Medicine and Hygiene 12: 334-337, 1963.

6. Kloetzel K. Mortality in chronic splenomegaly due to schistosomiasis mansoni: follow-up study in a Brazilian population. Transactions of the Royal Society of Medicine and Hygiene 61: 803-805, 1967.

7. Kloetzel K, Schuster NH. Repeated mass treatment of schistosomiasis mansoni: experience in hyperendemic areas of Brazil: I. Parasitological effects and morbidity. Transactions of the Royal Society of Tropical Medicine and Hygiene 81: 365-370, 1987.

8. Menezes Netto AG. Esplenectomia e derivação esplenorenal distal realizadas em Sergipe antes e após o Pro- grama Especial de Controle da esquistossomose (PECE). Revista da Sociedade Brasileira de Medicina Tropical 20: 41-43, 1987.

9. Pellon AB, Teixeira J. Distribuição geográfica da esquistossomose mansônica no Brasil. Divisão da Organização Sanitaria. Rio de Janeiro, 1950.

10. Prata A, Bina JC. Development of the hepatosplenic form of schistosomiasis (A study of 20 patients observed during a 5 year period). Gazeta Médica da Bahia 68: 4960, 1968.

11. Santos ML, Coura JR. Morbidade da esquistossomose no Brasil. IV - Evolução em pacientes tratados e seus controles. Memórias do Instituto Oswaldo Cruz 81: 53 $60,1986$.

12. Silveira AC. Controle da esquistossomose no Brasil. Memórias do Instituto Oswaldo Cruz 84 (supl. I): 91104, 1989. 